\title{
HUBUNGAN KARAKTERISTIK DENGAN TINGKAT ANSIETAS PADA SISWA-SISWI SMA
}

\author{
YuliaArdiyanti ${ }^{1}$, Livana $\mathbf{P H}^{2}$, Sih Ayuwatini ${ }^{3}$ \\ ${ }^{1}$ Akademi KeperawatanMuhammadiyah Kendal \\ ${ }^{2}$ Sekolah TinggillmuKesehatan Kendal \\ ${ }^{3}$ RSUD Dr H Soewondo Kendal \\ livana.ph@gmail.com
}

\begin{abstract}
Abstrak
UjianNasionalmerupakankeharusan yang harus dilakukan peserta didik sebagai syarat kelulusan sehingga menjadikan berbagai reaksi pada siswa salah satunya adalah ansietas.Penelitianbertujuanmengetahuihubungankarakteristikdengantingkatansieaspadasiswasiswi SMA.Penelitianmenggunakanmetodekuantitatifmenggunakandesain Study DeskripsiKorelasidenganpendekatan Cross Sectional.Sampelsebanyak 60 orang.Data dianalisismenggunakan Spearman Correlation.Hasilpenelitianmenunjukkantidakadahubunganantarausiadengantingkatansietasdanada hubunganntarajeniskelamindengantingkatansietas. Perluupayauntukmengatasiansietas agar siswadapatmenjalankanujiannasionaldenganlancar

Kata Kunci: ansietas, siswa-siswi, SMA

Abstract

National Examination is a necessity that must be done by students as a graduation requirement so as to make various reactions to students one of which is anxiety. The study aims to determine the relationship characteristic with ansieas level at high school students. The study used a quantitative method using the design of Study Description Correlation with the Cross Sectional approach. A sample of 60 people. Data were analyzed using Spearman Correlation. The results showed no relationship between age and level of anxiety and there was a relationship between sex and anxiety levels. Efforts are needed to overcome anxiety so students can run national exams smoothly
\end{abstract}

Keywords: anxiety, students, high school

\section{Pendahuluan}

UjianNasionalmerupakankeharusan

yang

harusdilakukanpesertadidiksebagaisyaratke lulusansehinggamenjadikanberbagaireaksi padasiswasalahsatunyaadalahansietas.Ansi etasmerupakangangguan mental terbesar, diperkirakan $20 \%$ daripopulasiduniamenderitaansietas

(Stuart, 2013).Menurut data National Institute of Mental Health (2005), di AmerikaSerikatdilaporkanbahwagangguan $\begin{array}{llll}\text { ansietasdiperkirakan } & 1 & \text { dari } & 10\end{array}$ orangmengalamiansietasPrevalensiansietas di Indonesia berkisarantara 2-5\% daripopulasiumumatau $\quad 7-16 \%$ darisemuapenderitagangguanjiwa. Indonesia merupakannegara yang setiaptahunprevalensiansietasnyamengala mipeningkatan (Hawari, 2011).
Ansietas yang terjadipadasiswa yang akanmenghadapiUjianNasionaladalah normal, namunsejauhmanasiswatersebutdapatmeng atasi rasa ansietasnya, tergantungpadakemampuansiswatersebutu ntukmeresponansietas yang dialaminya (Agustiar, 2010). Siswadenganmotivasiberprestasi yang tinggijugaakanmengalamikesulitandalamm eraihprestasi yang maksimalapabilasiswamemilikiperasantaku takankegagalanataumerasapanikdalammen ghadapiujian (Basuki, 2013).

$$
\text { Hasilpenelitian }
$$

dilakukanolehLastina (2013), menunjukkantingkatansietaspadasiswa SMA saatmenjelangujianyaitusiswa yang mempunyaiansietassedangsebanyak $53 \%$, siswamempunyaiansietasringansebanyak $33,3 \%$, dansiswa yang 
mempunyaiansietasberatsebanyak $\quad 6,7 \%$. Penelitian yang dilakukanolehAgustiar (2010) padaSISWA Kelas XII SMA menunjukkansiswamengalamiansietassaat menjelangujianpadatingkatsedangsebanyak $61,3 \%$, siswamempunyaiansietasringansebanyak 26,5\%, dansiswa yang mempunyaiansietasberatsebanyak $5,3 \%$. Hal tersebutmenunjukkanbahwasiswasiswisaatmenjelangujianmengalamiansietas daritingkatringansampaisedangdenganfakt orpemicuansietasmenghadapiujiandiantara nyaketerbatasanwaktu,

tingkatkesulitanmaterites, instruksites (Swasti, 2013).

Selaindariketigahal di atas, faktorpentinglainnya yang jugamenjadipemicuansietassiswadalamme nghadapiujianadalahansietas yang cenderungmeningkatseiringdengantingginy ajenjangpendidikan.Artinya, siswa SMA yang

menghadapiujianakanmenghadapitingkatan sietas yang lebihtinggidaripadasiswa SD maupun SMP. Selanjutnya, penelitian yang melibatkanberbagaibudaya (cross cultural research)

membuktikanbahwamakinbesarperansebua hujian, makinbesar pula tingkatansietas yang ditimbulkannyaterhadappesertaujian (Hill, 1980 dalamSwasti, 2013).Bagisiswa SMA hasil

UN tidakhanyamenentukanditerimanyamereka padasekolahlanjutantetapijugaturutmenent ukansaatberkompetisidalamseleksimemper olehpekerjaan

(Swasti, 2013).Berdasarkanlatarbelakangdiatasperlu nyapenelitianterkaithubungankarakteristikd engantingkatansietassiswadalammenghada piujiannasional.

\section{Metode}

Penelitianinimerupakanpenelitian $K u$ antitatifmenggunakandesainStudy

DeskripsiKorelasidenganpendekatanCross Sectional.Sampelsebanyak 60 orang yang diambildenganmenggunakanmetode

Stratified Random Samplingpadasiswasiswi di SMA Kendal. Tingkat ansietassiswa/siswidiukurmenggunakan

HRS-A (Hamilton Rating Scale for Anciety).UjiinstrumenHRS-

ApernahdilakukanolehRohmah

(2007).Hasilujivaliditasperhitungantiap

item adalahdalamrentang 0,500-0,929 (rhitung), hasiltersebutlebihbesarbila di bandingkandengan $\quad 0,444 \quad$ (rtabel), danhasilujireliabilitasadalah 0,9366 (nilai alpha), sehinggadapatdinyatakanbahwa HRS-A handal, stabilsertakonsistendalammengukuransieta s.Analisa data yang digunakanadalahunivariatdanbivariatmeng gunakananalisisSpearman Correlation.

\section{Hasil}

Tabel 1.

Karakteristik usia responden $(n=60)$

\begin{tabular}{ccccc} 
& Variabel & Mean & Std. Deviation & Min - Max \\
\hline Usia & 16 & 1,01 & $15-19$ \\
\hline
\end{tabular}

Tabel 2.

Karakteristik jenis kelamin responden $(n=60)$

\begin{tabular}{lcc}
\hline \multicolumn{1}{c}{ Jenis kelamin } & $\mathrm{f}$ & $\%$ \\
\hline Laki-laki & 16 & 26,7 \\
Perempuan & 44 & 73,3 \\
\hline
\end{tabular}

Tabel 3.

Tingkat stres responden $(n=60)$

\begin{tabular}{ccc}
\hline Karakteristik Responden & $\mathrm{f}$ & $\%$ \\
\hline Ringan & 14 & 23,3 \\
\hline
\end{tabular}




\begin{tabular}{lll}
\hline Sedang & 29 & 48,3 \\
Berat & 17 & 28,4 \\
\hline
\end{tabular}

Tabel 3.

Tingkat stres responden $(\mathrm{n}=60)$

\begin{tabular}{|c|c|c|c|c|c|}
\hline \multirow[t]{3}{*}{ Variabel } & \multicolumn{4}{|c|}{ Ansietas } & \multirow[t]{3}{*}{$P$ value } \\
\hline & \multicolumn{2}{|c|}{ Ringan-sedang } & \multicolumn{2}{|c|}{ Berat } & \\
\hline & $\mathrm{f}$ & $\%$ & $\mathrm{f}$ & $\%$ & \\
\hline Usia & \multirow[b]{2}{*}{43} & \multirow[b]{2}{*}{71,6} & \multirow[b]{2}{*}{17} & \multirow[b]{2}{*}{28,4} & 0,15 \\
\hline Jeniskelamin & & & & & 0,04 \\
\hline
\end{tabular}

\section{Pembahasan}

Hasilpenelitianmenunjukkanbahwati dakadahubunganantarakarakteristikusiaden gantingkatansietassiswa (p-value >0,05). Hasilpenelitianmenunjukkanusiasiswasiswi rata-rata berusia 16 tahun, denganrentangusia 15 hingga 19 tahundimanausiatersebutmerupakanusiare maja. Menurut WHO bahwarentangusiamasaremajayaitumasare majaawalberusiaantara 10-14 tahun, masaremajapertengahanberusiaantara 1519 tahun, danmasaremajaakhirberusiaantara 20-24 tahun (Sumiati, 2009).Masaremajaawal (early adolescence) adalahmasadimulainyaperkembanganpikira n-pikiranbaru, perubahancaraberpikir, peransosial, emosi yang menjadikurangstabil, dansebagainya (Semiun, 2006).

Sedangkanpadamasaremajapertengahan, menurut Erikson (1996, dalam Hurlock, 2010)

merupakandimulainyapembentukanidentita s, sehinggapadamasainimenjadimasa "krisisidentitas", yang berartimasadimanasuatumanusiauntukperta makalinyasecara definitive harusmenentukanapakahdansiapakahdiapa damasadepan. Penelitian Hill (1980 dalamSwasti, 2013) jugadisebutkanbahwasiswa SMA yang menghadapiujianakanmenghadapitingkatan sietas yang lebihtinggidaripadasiswa SD maupun SMP. Hal tersebutdipengaruhiolehbesarringannyaper ansebuahujian, makinbesar pula tingkatansietas yang ditimbulkannyaterhadappesertaujian.Bagisi swa SMA hasil UN tidakhanyamenentukanditerimanyamereka padasekolahlanjutantetapijugaturutmenent ukansaatberkompetisidalamseleksimemper olehpekerjaan (Swasti, 2013).

Hasilpenelitianmenunjukkanproporsi berdasarkanjeniskelaminsiswasiswisebagianbesaradalahperempuanyaitus ebanyak $44 \quad(73,3 \%)$ danlaki-laki 16 $(26,7 \%)$

responden.Hasilanalisisbivariatmenunjukk anadahubunganantarajeniskelamindenganti ngkatansietas ( $\mathrm{p}$ value $<0,05$ ). Penelitian dari para ahli tentang studi ansietassecara umum, menyatakan bahwa perempuan lebih ansietas dari pada laki-laki (Craig, 2009). Perempuan lebih cemas akan ketidakmampuannya dibanding dengan laki-laki, laki-laki lebih aktif, eksploratif, sedangkan perempuan lebih sensitif (Durand, 2006). Hasil penelitian lain (Leary, 1982 dalam Nopan, 2010) menyatakan bahwa perempuan memiliki skor yang lebih tinggi pada pengukuran ketakutan dalam situasi sosial dibanding pria. Perempuan lebih mudah dipengaruhi oleh tekanan-tekanan lingkungan dari pada laki-laki, perempuan juga lebih ansietas, kurang sabar, dan mudah mengeluarkan air mata.

Hasil penelitian juga menunjukkan siswa-siswilaki-laki sebanyak $6 \quad(66,7 \%)$ responde mengalami ansietasn, sedangkan perempuan sebagian besar mengalami 
ansietas sedang yaitu sebanyak $5(55,6 \%)$ responden. Ansietas lebih banyak terjadi pada siswa perempuan karena psikologis seorang perempuan mudah labil sehingga mempengaruhi persepsi terhadap stimulus atau masalah yang dihadapi, hal ini menjadikan seorang perempuan lebih mudah mengalami ansietas (Hawari, 2011).Berdasarkanteori yang telahdipaparkan,

siswiperempuanlebihtinggitingkatansietasn yadibandingkandengansiswalaki-laki.

Perbedaantingkatansietas yang dimilikiolehperempuankarena psikologis seorang perempuan mudah labil. Perempuan lebih mudah dipengaruhi oleh tekanan-tekanan lingkungan dari pada lakilaki, perempuan juga lebih cemas, kurang sabar, dan mudah mengeluarkan air mata.

\section{Simpulandan Saran}

berusia

Karakteristikresponden rata-rata

dansebagianbesarperempuan.Tingkat

ansietassiswa-

siswimenjelangujiannasionalmayoritaspada kategoriansietassedang.Perlunyaupayauntu kmengatasiansietaspadasiswasiswi agar dapatmenjalankanujiannasionaldenganlanc ar.

\section{Daftar pustaka}

Agustiar.

(2010).

KecemasanMenghadapiUjianNasion al Dan MotivasiBelajarPadaSiswaKelas Xii SmaNegeri "X" Jakarta Selatan. JurnalPsikologi Volume 8 Nomor 1, Juni

2010.Diaksesmelaluihttp://ejurnal.es aunggul.ac.id/index.php/Psi/article/v iewFile /76/73padatanggal 2 Oktober 2015.

Basuki.(2013). Pemanfaatan Self Hypnosis DalamMenurunkanKecemasanMaha siswa Di AkademiKeperawatanKabupatenPur worejo.Electronic Theses \& Dissertations (ETD) GadjahMada
University.Diaksesmelaluihttp://etd.r epository.ugm.ac.id/index.padatangg al 2 Oktober 2015.

Craig, T. D. (2009). ABC Kesehatan Mental.In A. S. Hale, Ansietas(p. 60). Jakarta: EGC.

Hawari, D. (2011). ManajemenStres, Cemas Dan Depresi. Jakarta: FKUI.

Hendriyanto.

(2012).

PengaruhHipnoterapiTerhadap

Tingkat

StresMahasiswaFakultasIlmuKepera watanUniversitasPadjadjaran. Stude nts e-journals Vol 1, No 1 (2012). Diaksesmelalui: http://journal.unpad. ac.id/ejournal/article/view/715/761pa datanggal 2 Oktober 2015.

Hurlock, Elisabeth.

(2010). PsikologiPerkembanganEdisiKelima. Jakarta: Erlangga.

Lastina.(2013).

HubunganAntaraDukunganSosialden ganKecemasanMenghadapiUjianNas ionalPadaSiswa SMA Negeri 2 Kota Magelang.JurnalEloctronicsFakultas

Psikologi UNDIP Vol 2, No 3 (2013)diaksesmelaluihttp://ejournals1.undip.ac.id/index.php/empati/artic le/ view/7360/7120 padatanggal 2 Oktober 2015.

National Institute of Mental Health.(2015). Anxiety and College Students. NIMH: 1-8

Semiun,

Yustinus. (2006). Teorikepribadiandanterapips ikoanalitik Freud. Yogyakarta: Kanisius.

Rohmah.(2007). Tingkat KecemasanPadaPenderitaHipertensi Di

DesaPurworejoKecamatanRinginaru mKabupaten Kendal.Skripsi STIKES Kendal. 
Stuart, G.W. (2013).

BukuSakuKeperawatanJiwa. (Ed.5). Jakarta: EGC

Swasti, K.G., Helena, C.D., Pujasari, H. (2013).

PenurunanAnsietasDalamMenghada piUjianNasionalPadaSiswaKelas XII SMAN

\section{$X$}

MelaluiPemberianTerapiSuportif.Jur nalKeperawatanSoedirman (The Soedirman Journal of Nursing), Volume 8, No.2, Juli 2013. 